\title{
Ultrasonographic Characteristics of Diabetes Impacts in Kidneys' Morphology
}

\author{
Mohammed A. Ali Omer1,2, Ayman H. Eljack', Mohamed E. M. Gar-alnabi', \\ Mustafa Z. Mahmoud ${ }^{3}$, Muatasim Elseid ${ }^{1}$, Ghada A. Edam ${ }^{1}$ \\ ${ }^{1}$ College of Medical Radiologic Science, Sudan University of Science and Technology, Khartoum, Sudan \\ ${ }^{2}$ College of Applied Medical Science, Department of Radiology, Qassim University, Buraidah, Saudi Arabia \\ ${ }^{3}$ Radiology and Medical Imaging Department, College of Applied Medical Sciences, Salman bin Abdulaziz \\ University, Al-Kharj, Saudi Arabia \\ Email: alkajam@gmail.com
}

Received 15 September 2014; revised 10 October 2014; accepted 24 October 2014

Copyright (C) 2014 by authors and Scientific Research Publishing Inc.

This work is licensed under the Creative Commons Attribution International License (CC BY). http://creativecommons.org/licenses/by/4.0/

(c) (i) Open Access

\begin{abstract}
A total sample size consisting of 150 Diabetic male patients has been investigated by ultrasound system General Electric using gray-scale B-mode imaging with curvilinear transducer $3 \mathrm{MHz}$ to assess the impact of diabetes in kidney morphology and it is distributed in Sudan. The collected data were the patient age, height, weight, kidneys size, ultrasound findings of involved kidneys, and duration of diabetes and residence region. The analyzed data show that the diabetes has been as endemic disease in central Sudan (Khartoum \& Jazeera) representing $55 \%$ and in the west of Sudan representing $38 \%$. The BMI of diabetic patients has been significantly $\left(R^{2}=0.6\right)$ decreasing following aging. The kidney size increases significantly as $R^{2}=0.75$ and 0.6 for left and right kidney respectively. Their correlation is fitted in the following equations: $y=3.95 x+27.26$ and $y=$ $2.41 x+35.12$ for the left and right kidney respectively. The impact of duration was a reduction in size significantly as $R^{2}=0.61$ and 0.55 with a correlation fitted in the following equations: $y=$ $-2.22 x+139.9$ and $y=-1.51 x+96.59$ for the left and right kidney respectively. The mean kidney length was $(14.5 \mathrm{~cm})$ and the renal cortex in the range of $2-2.3 \mathrm{~cm}$, the kidneys size were so enlarged as $92.4 \pm 11.7$ and $121 \pm 17.1$ for the right and left kidney respectively while in late case of Diabetes, the kidney is more echogenic, atrophied size with loss of corticomedullary differentiation.
\end{abstract}

\section{Keywords}

Ultrasound, Kidneys, Morphology, Diabetes, Impacts 


\section{Introduction}

In this paper, a total sample size consisting of 150 Diabetic male patients has been investigated by ultrasound system General Electric. Sample of diabetes distribution, age, kidney size, BMI and sonographic appearance of diabetes impact in renal morphology were given and discussed.

Diabetes mellitus is a syndrome of impaired carbohydrates, fat and protein metabolism caused by either lack of insulin secretion or decreased sensitivity of the tissue to insulin. There are two general types of diabetes mellitus. Type 1 diabetes, also called Non-Insulin Dependent Diabetes Mellitus (NIDDM), is caused by lack of insulin secretion. Type 2 Diabetes, also called Insulin Dependent Diabetes Mellitus (IDDM), is caused by decreased sensitivity of target tissue to metabolic effect of insulin. This reduced sensitivity to insulin is called insulin resistance. In both types of diabetes mellitus, metabolism of all foodstuffs is altered. Basic effect of insulin lack or insulin resistance on glucose metabolism is to prevent the efficient uptake and utilization of glucose by most cells of the body, except those of the brain. As a result, blood glucose concentration increases, cell utilization of glucose falls increasingly lower, and utilization of fats and proteins increases [1]. Also the chronic hyperglycemia of diabetes is associated with long-term damage, dysfunction and failure of different organs, especially the eyes, kidneys, nerves, heart and blood vessels [2]. About 347 million people worldwide have diabetes [3]. In 2004, an estimated 3.4 million people died from consequences of high fasting blood sugar [4]. More than $80 \%$ of diabetes deaths occur in low- and middle-income countries [5], and what should be consider seriously in the future is the state of WHO projects that expect diabetes will be the 7th leading cause of death in 2030 [6]. Also the Diabetes increases the risk of heart disease and stroke; $50 \%$ of people with diabetes die of cardiovascular diseases (primarily heart disease and stroke [7]. It could be combined with reduced blood flow. Neuropathy in the foot increases the chance of foot ulcers, infection and eventual need for limb amputation. Moreover, a Diabetic retinopathy is an important cause of blindness, and occurs as a result of long-term accumulated damage to the small blood vessels in the retina. About one percent of global blindness can be attributed to diabetes [8]. It could also lead to kidney failure [6] and is considered as the overall risk of dying among people with diabetes relative to healthy ones [9]. The consequences of diabetes, such as coronary artery and peripheral vascular disease, stroke, diabetic neuropathy, amputations, renal failure, reduced life expectancy and enormous health costs for virtually every society, have been increasingly notable [1]. An increase in body fat is generally associated with an increase in risk of metabolic diseases such as Type 2 diabetes mellitus, hypertension and dyslipidaemia [10]. Body mass index (BMI) criteria are currently the primary focus on obesity treatment recommendations, with different treatment cutoff points based upon the presence or absence of obesity-related concomitant disease [10].

The detection of diabetes could be carried out by different methods, such as cretinine level in blood and sugar level, in addition to ultrasound as non invasive tool. In the assessment of diabetes impact on kidney's morphology using ultrasound, Saddig et al. [11] showed that there was abnormal renal echogenicity with nephropathy Grade 1 which was so greater than Grade 2 that showed decreased renal size among diabetic patients as highlighted in Figure 1.



(a)

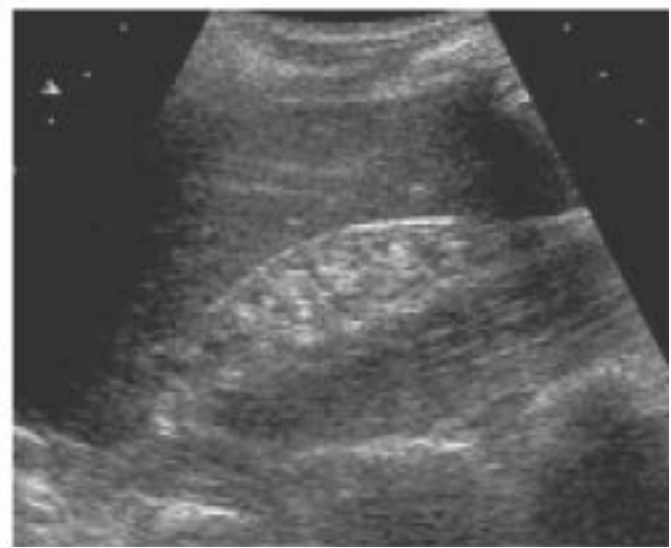

(b)

Figure 1. The abnormal renal parenchymal echogenicity: (a) Grade 1 nephropathy high echogenicity; (b) Grade 3 nephropathy (also notice the small renal size in (a) due to chronic nephropathy) [11]. 
Also, the utilization of ultrasound to evaluate the presence of nephropathy, due to diabetes, has been highlighted by Hricak et al. [12] and Fiorini and Barozzi [13] in which they evaluate it by comparing the echogenicity of the renal cortex, medulla and pyelic sinus with that of the adjacent liver and spleen (assuming that the liver and spleen present normal echogenicity). Echogenicity is divided into four different grades from 0 to 3: a) parenchyma appears hypoechoic when compared with the liver parenchyma; b) parenchyma appears isoechoic when compared with the liver parenchyma; c) parenchyma appears hyperechoic when compared with the liver parenchyma.

A renal ultrasound is typically obtained to measure the renal size and echogenicity. Renal enlargement may be seen early in diabetes due to hyper filtration, while in late stages the kidneys diminish in size from glomerulosclerosis. In addition, renal cortical hyperechogenicity is seen suggesting deteriorated renal function. Ultrasound is also used to exclude non diabetes-related renal disorders, e.g. renal stones, masses or hydronephrosis [11] [14].

Renal length and volume measurements are clinically relevant, serving as surrogates for renal functional reserve, and are used frequently as the basis for making clinical decisions. Serial measurements can also provide information regarding disease progression or stability. A number of reports have described ultrasonography measurement of renal length and volume in the healthy Western population [15] [16], but there are scant data regarding MR measurement of renal dimensions in adults.

The kidney size of a patient is a valuable diagnostic parameter in urological and nephrologic practice, while the leading anatomy text describes the adult kidney as $12 \mathrm{~cm}$ long, $6 \mathrm{~cm}$ wide and $3 \mathrm{~cm}$ deep [17]. Further review of the literature shows that the renal size varies with age, gender, body mass index, pregnancy and concomitant conditions. Renal size may be an indicator for the state kidney and therefore, kidney function or physiology [18] [19], and it is valuable in monitoring unilateral kidney disease through comparison with the other, uninvolved one i.e., the healthy kidney [20]. Also, an increased BMI $\left(25 \mathrm{~kg} / \mathrm{m}^{2}\right)$ has been associated with increased prevalence of diabetes mellitus, hypertension and dyslipidaemia [10]. The impact of diabetes in renal system can also appear as a change in cortical echogenesity and thickness in case of diabetic nephropathy relative to normal ones that have been mentioned by Benjamin et al. [21] in which they found that the kidney lengths were $12.4 \pm$ $0.9 \mathrm{~cm}$ for men and $11.6 \pm 1.1 \mathrm{~cm}$ for women, and that kidney volumes were $202 \pm 36 \mathrm{ml}$ for men and $154 \pm 33$ $\mathrm{ml}$ for women.

\section{Method}

A total sample size consists of 150 Diabetic male patients have been investigated by ultrasound system General Electric. The examinations were done using gray-scale B-mode imaging with curvilinear transducer $3 \mathrm{MHz}$ for the patients who have been referred for renal system scanning. Their average age was $46.9 \pm 8.8$ years old. The aim of selecting this sample was to assess the distribution of diabetes in Sudanese male and the impact of diabetes in renal morphology. The scanning was performed from posterior-lateral direction for obese patient and anterio-lateral direction for thin patients. The collected data was patient age, height, weight, kidneys size, ultrasound findings of involved kidneys, duration of diabetes and residence region. The kidneys sizes were calculated from the multiplication of width and length. Then the collected data has been analyzed in form of bar\% and correlation of scatter plot.

\section{Results}

The following results shows the analysis of diabetic impact on renal morphology in Sudanese sample and the regional distribution of diabetes in Sudan: Figure 2 shows the sample of diabetes distribution in the regions of Sudan during 2010; Figure 3 shows the correlation between age in yeas and BMI in $\left(\mathrm{Kg} / \mathrm{m}^{2}\right)$; Figure 4 shows the correlation between BMI in $\left(\mathrm{Kg} / \mathrm{m}^{2}\right)$ and kidney size in $\mathrm{cm}$; Figure 5 shows the correlation between duration in years and kidney size in cm; Figure 6 shows the sonographic appearance of diabetes impact in renal morphology.

\section{Discussion}

Figure 2 shows the sample of diabetes distribution in the regions of Sudan in 2010. It reveals that the most endemic sector was the central of Sudan taking a 55\% relative to other sectors; such high incidence could be ascribed to intake of high unrefined carbohydrates and fat, populated sector and lifestyle. Also the frequency has 


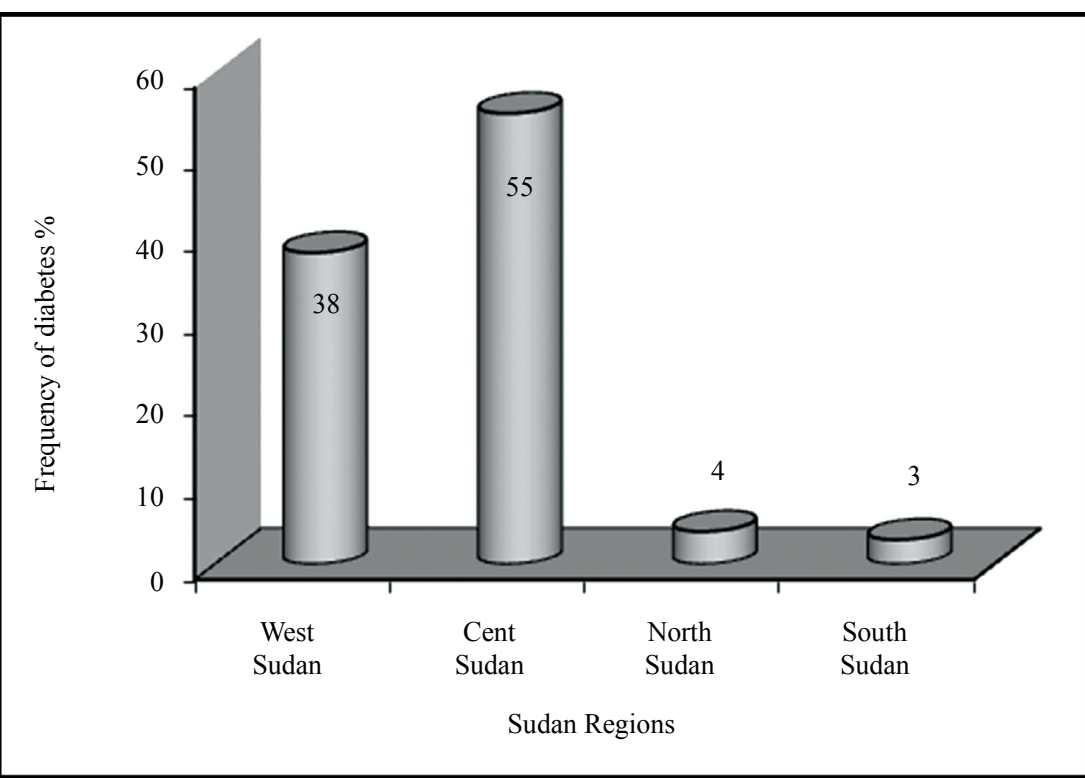

Figure 2. The sample of diabetes distribution in the regions of Sudan in 2010.

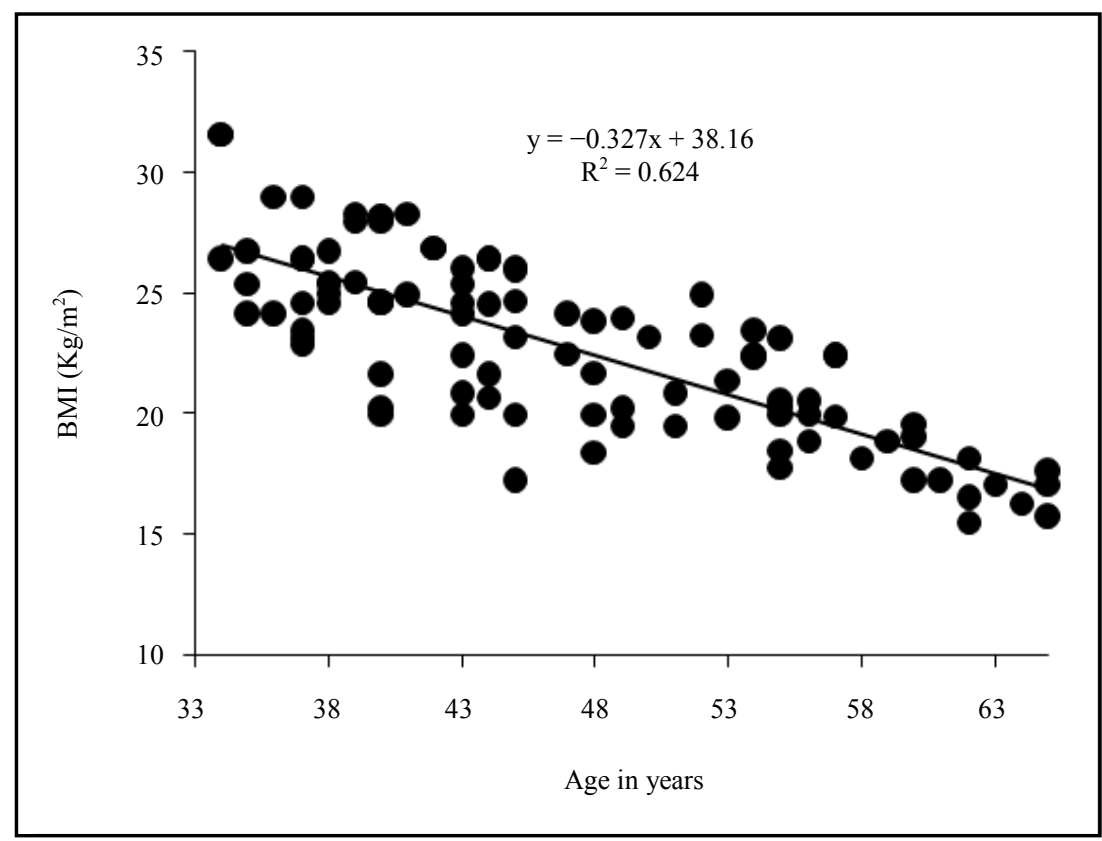

Figure 3. The correlation between age in yeas and BMI in $\left(\mathrm{Kg} / \mathrm{m}^{2}\right)$.

been observed highly in Western Sudan taking a 38\% which could be ascribed to ongoing economic deterioration in Western Sudan, the difficulties faced by people in accessing modern health facilities and the shortage of anti-diabetes drugs further reinforce the role of traditional systems of healing [22].

Figure 3 shows the correlation between age in yeas and BMI in $\left(\mathrm{Kg} / \mathrm{m}^{2}\right)$, it reveals that the BMI decreases in a linear form following the aging among diabetic patients and its relation could be fitted in the following equations: $y=-0.33 x+38.16$, where $y$ refers to BMI and $x$ refers to age in years. Such correlation is significant as $\mathrm{R}^{2}=0.6$, the decreasing phenomena could be ascribed to the decreasing of function which in turn influenced by a reduction in nitric oxide production (a potent vasodilator) in tissues [23]. In addition, there is a reduction in beta adrenergic receptor sensitivity associated with the aging process [24] which in turn reducing the ability of the sympathetic nervous system to respond to stress [25]; however this result is reversed to normal relation between 


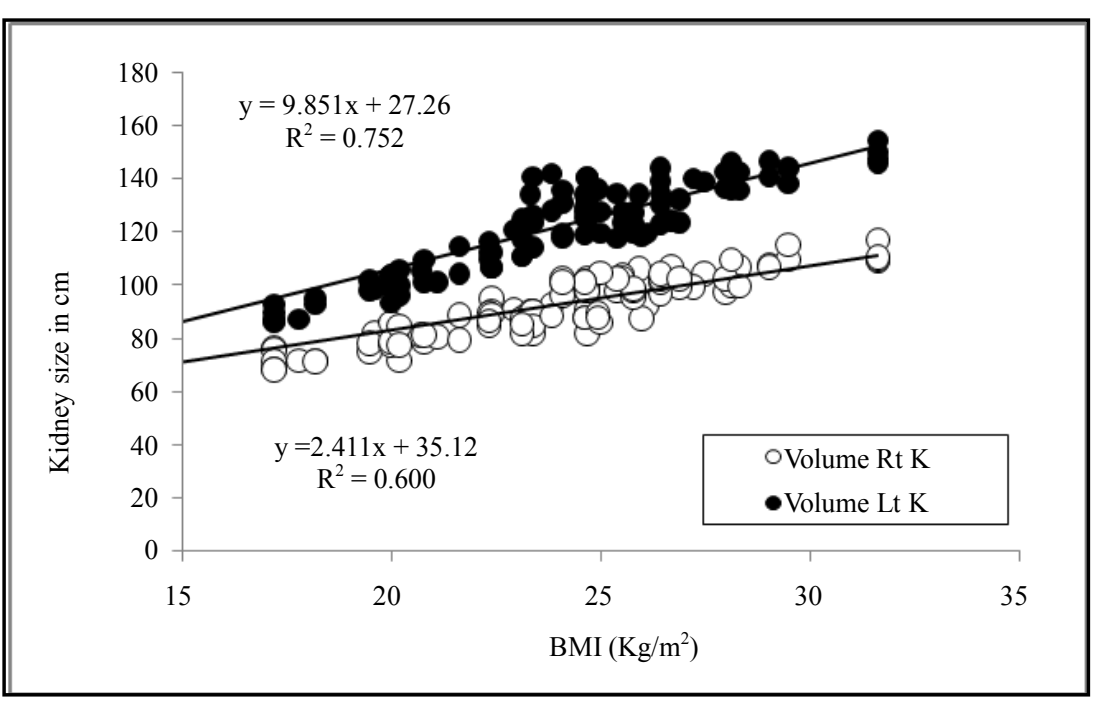

Figure 4. The correlation between BMI in $\left(\mathrm{Kg} / \mathrm{m}^{2}\right)$ and kidney size in $\mathrm{cm}$.

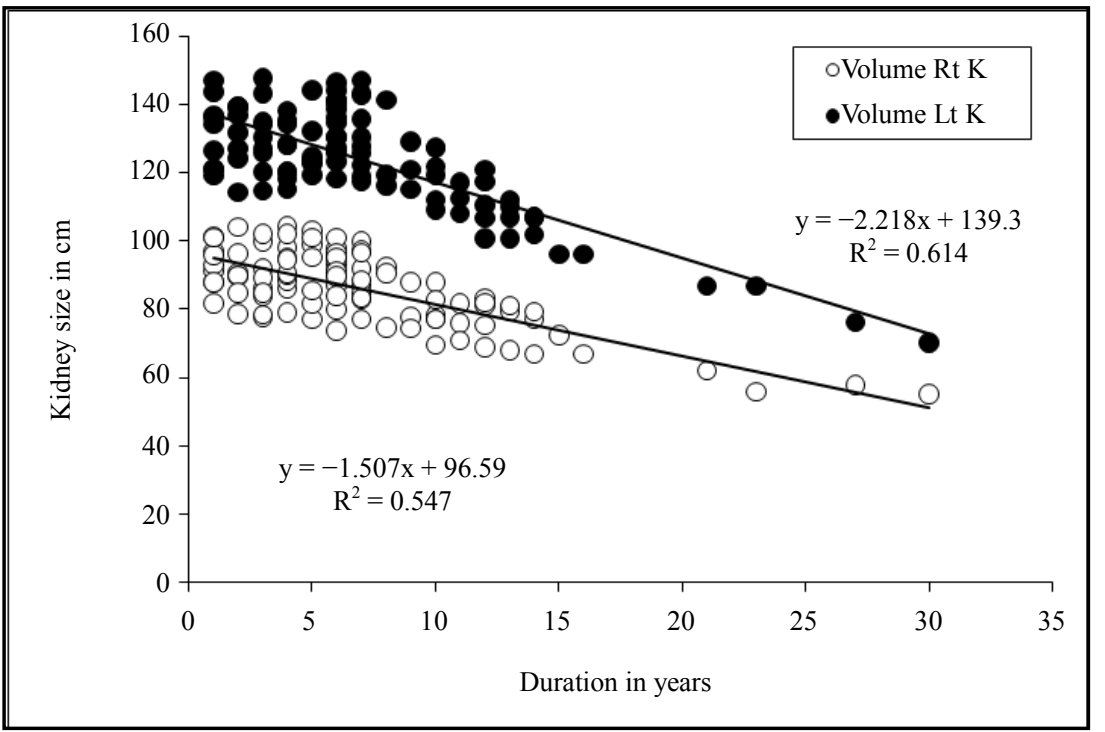

Figure 5. The correlation between duration in years and kidney size in $\mathrm{cm}$.
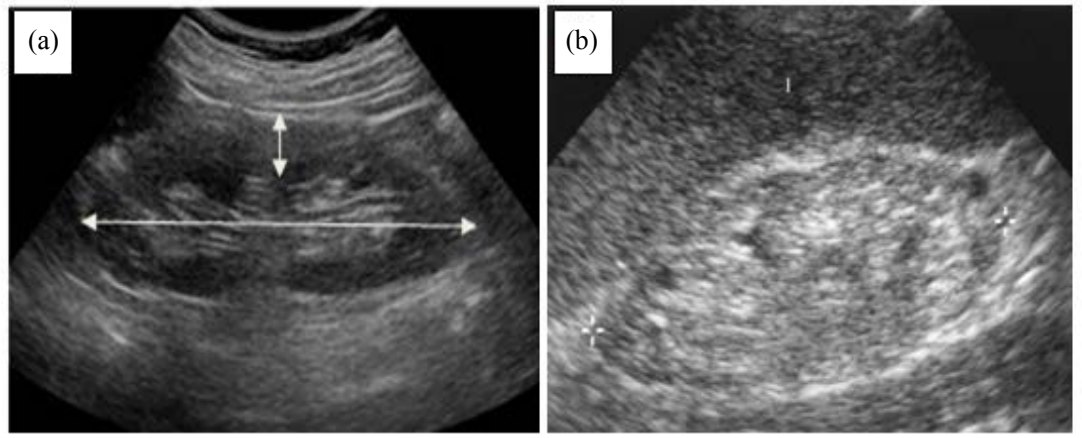

Figure 6. The sonographic appearance of diabetes impact in renal morphology: (a) cortex enlargement and atrophied medulla and the renal enlargement greater than 14.5 $\mathrm{cm}$; (b) late case in which the kidney is more echogenic with loss of corticomedullary differentiation, the patient requiring dialysis or kidney transplantation. 
BMI and aging as mention by Forbes et al. [26]. Also failure to use glucose for energy leads to increased utilization and decreased storage of proteins as well as fats. There for a person with untreated diabetes mellitus suffers rapid weight loss and asthenia (lack of energy) despite eating large amounts of food (polyphagia). Without treatment, these metabolic abnormalities can cause severe wasting of the body tissues and death within a few weeks [1].

Figure 4 shows the correlation between BMI in $\left(\mathrm{Kg} / \mathrm{m}^{2}\right)$ and kidney size in $\mathrm{cm}$, it shows that the Kidneys size increases following the BMI increment among diabetic patients in a form of linear relationship fitted in equations: $y=3.95 x+27.26$ and $y=2.41 x+35.12$ for the left and right kidney respectively, such correlation is so significant as $\mathrm{R}^{2}=0.75$ and 0.60 respectively. Same correlation has been obtained by Raza et al. [27]. The study also reveals that the left kidney is bigger than the right one as mentioned by Odita and Ugbodaga [28] and Mário et al. [29]. The increment of kidneys size or hypertrophy could be ascribed to sort of physiological compensation to meet the high filtrated components from the blood stream.

Figure 5 shows the correlation between duration of diabetes in years and kidney size in $\mathrm{cm}$. It reveals that the kidneys size has been decreases following the duration of the disease (diabetes) in a linear form fitted in equations: $y=-2.22 x+139.3$ and $y=-1.51 x+96.59$ for the left and right kidney respectively with significant correlation as $\mathrm{R}^{2}=0.61$ and 0.55 respectively. However the renal hypertrophy has been observed during the early stage only and gradual reduction in size following the long duration. In this realm, Inomata [30] stated that in humans diabetic renal hypertrophy can persist for several years despite good glucose control, which could be ascribed to the compensation of the kidney to clear threefold incidence of micro-albumin urea and almost threefold faster decline in GFR during the 9 years [31]. Other investigators have related an increase in kidney size with an increased glomerular filtration rate in early stage diabetes mellitus while size shrinking occur in late stages which is consider as a main mark for renal failure.

Figure 6 shows the sonographic appearance of diabetes impact in renal morphology, in which the mean kidney length was $14.5 \mathrm{~cm}$, an enlarged renal cortex in the range of $2-2.3 \mathrm{~cm}$ and atrophied medulla (a) and (b) late case in which the kidney is more echogenic with loss of corticomedullary differentiation, the patient requiring dialysis or kidney transplantation. Also the mean renal enlarged size was $92.4 \pm 11.7$ and $121 \pm 17.1$ for the right and left kidney respectively. Such results are relative to common normal cases that showed a renal cortex thickness of $1.0-1.6 \mathrm{~cm}$ and a kidney length of $9.2-10.8 \mathrm{~cm}$ as mentioned by Adibi et al. [32] and Michael et al. [33] who found that: the mean cortical thickness was $5.9 \mathrm{~mm}$ (range, $3.2-11.0 \mathrm{~mm}$ ) and the mean kidney length was $10 \mathrm{~cm}(7.2-12.4 \mathrm{~cm})$.

\section{Conclusion}

The ultrasound scanning has been the best choice for abdominal diagnosis and diseases assessment. It reveals that the diabetes has direct impact on kidney morphology in view of renal volume enlargement and cortical thickening in early stage, then atrophied and echogenic in late stage. Also there is a significant correlation between kidney size and the BMI in a linear form as $\mathrm{R}^{2}=0.8$ and 0.6 for left and right kidney respectively as well as the kidney size versus duration with $\mathrm{R}^{2}=0.6$ and 0.5 for left and right kidney respectively [34]-[36]. Such finding could be utilized successfully to assess the diabetes severity and stage as well as to determine the treatment model.

\section{References}

[1] Guyton, A.C. and Hall, J.E. (2006) Text Book of Medical Physiology. 11th Edition, Elsevier Saunders, Philadelphia, 972.

[2] Dabla, P.K. (2010) Renal Function in Diabetic Nephropathy. World Journal of Diabetes, 1, 48-56. http://dx.doi.org/10.4239/wjd.v1.i2.48

[3] Danaei, G., Finucane, M.M., Lu, Y., Singh, G.M., Cowan, M.J. and Paciorek, C.J. (2011) National, Regional, and Global Trends in Fasting Plasma Glucose and Diabetes Prevalence since 1980: systematic Analysis of Health Examination Surveys and Epidemiological Studies with 370 Country-Years and 2.7 Million Participants. The Lancet, 378, 31-40. http://dx.doi.org/10.1016/S0140-6736(11)60679-X

[4] World Health Organization Global Health Risks (2009) Mortality and Burden of Disease Attributable to Selected Major Risks. WHO Global Health Risks, Geneva.

[5] Mathers, C.D. and Loncar, D. (2006) Projections of Global Mortality and Burden of Disease from 2002 to 2030. PLoS 
Medicine, 3, e442. http://dx.doi.org/10.1371/journal.pmed.0030442

[6] World Health Organization (2011) Global Status Report on Non-Communicable Diseases 2010. WHO, Geneva.

[7] Morrish, N.J., Wang, S.L., Stevens, L.K., Fuller, J.H. and Keen. H. (2001) Mortality and Causes of Death in the WHO Multinational Study of Vascular Disease in Diabetes. Diabetologia, 44, S14-S21. http://dx.doi.org/10.1007/PL00002934

[8] World Health Organization (2012) Global Data on Visual Impairments 2010. WHO, Geneva.

[9] Roglic, G., Unwin, N., Bennett, P.H., Mathers, C., Tuomilehto, J. and Nag, S. (2005) The Burden of Mortality Attributable to Diabetes: Realistic Estimates for the Year 2000. Diabetes Care, 28, 2130-2135. http://dx.doi.org/10.2337/diacare.28.9.2130

[10] Bays, H.E., Chapman, R.H. and Grandy, S. (2007) The Relationship of Body Mass Index to Diabetes Mellitus, Hypertension and Dyslipidaemia: Comparison of Data from Two National Surveys. International Journal of Clinical Practice, 61, 737-747. http://dx.doi.org/10.1111/j.1742-1241.2007.01336.x

[11] Jastaniah, S.D., Alsayed, N.M., Awad, I.A., Fida, H.R. and Elniel, H.H. (2013) Evauation of Renal Disorders in Type 2 Diabetic Patients Using Ultrsonography. Open Journal of Medical Imaging, 3, 165-170. http://dx.doi.org/10.4236/ojmi.2013.34024

[12] Hricak, H., Cruz, C., Romanski, R., Uniewski, M.H., Levin, N.W. and Madrazo, B.L. (1982) Renal Parenchymal Disease: Sonographice Histologic Correlation. Radiology, 144, 141-147. http://dx.doi.org/10.1148/radiology.144.1.7089245

[13] Fiorini, F. and Barozzi, L. (2007) The Role of Ultrasonography in the Study of Medical Nephropathy. Journal of Ultrasound, 10, 161-167. http://dx.doi.org/10.1016/j.jus.2007.09.001

[14] Van Den Noortgate, N., Velghe, A., Petrovic, M., Vandewiele, C., Lameire, N., Voet, D. and Afschrift, M. (2003) The Role of Ultrasonography in the Assessment of Renal Function in the Elderly. Journal of Nephrology, 16, 658-662.

[15] Allan, P., Meire, H., Cosgrove, D., Dewbury, K. and Farrant, P. (2001) The Normal Kidney. In: Clinical Ultrasound: A Comprehensive Text, 2nd Edition, Churchill Livingstone, New York, 513-528.

[16] Bakker, J., Olree, M., Kaatee, R., de Lange, E.E., Moons, K.G., Beutler, J.J. and Beek, F.J.A. (1999) Renal Volume Measurements: Accuracy and Repeatability of US Compared with That of MR Imaging. Radiology, 211, 623-628. http://dx.doi.org/10.1148/radiology.211.3.r99jn19623

[17] Standring, S., Borley, N.R., Collins, P., Crossman, A.R. and Gatzoulis, M.A. (2008) The Anatomical Basis of Clinical Practice (Gray's Anatomy). 4th Edition, Churchill Livingstone, Edinburgh.

[18] Shcherbak, A.L. (1989) Angriographic Criteria in the Determination of Indications for Organ Preserving Surgery in Renal Artery Occlusion. Klinicheskaia Khirurgiia, 2, 5.

[19] Guzman, R.P., Zierler, R.E., Isaacson, J.A., Bergelin, R.O. and Strandness Jr., D.E. (1994) Renal Atrophy and Arterial Stenosis. A Prospective Study with Duplex Ultrasound. Hypertension, 23, 346-347. http://dx.doi.org/10.1161/01.HYP.23.3.346

[20] Yamaguchi, S., Fujii, H. and Kaneko, S. (1990) Ultrasonographic Study in Patients with Chronic Renal Failure. Part 1. Ultrasonic Measurement of Renal Size and Analysis of Renal Ultrasonotomograms. Nippon Hinyokika Gakkai Zasshi, 81, 1175-1177.

[21] Cheong, B., Muthupillai, R., Rubin, M.F. and Flamm, S.D. (2007) Normal Values for Renal Length and Volume as Measured by Magnetic Resonance Imaging. Clinical Journal of the American Society of Nephrology, 2, 38-45. http://dx.doi.org/10.2215/CJN.00930306

[22] Ahmed Awad, M. (2006) Diabetes Care in Sudan Emerging Issues and acute Needs. Diabetes Voice, 51, 1-15.

[23] Stadler, K., Jenei, V., von Bolcshazy, G., Somogyi, A. and Jakus, J. (2003) Increased Nitric Oxide Levels as an Early Sign of Premature Aging in Diabetes. Free Radical Biology \& Medicine, 15, 1240-1251. http://dx.doi.org/10.1016/S0891-5849(03)00499-4

[24] Schutzer, W.E. and Mader, S.L. (2003) Age-Related Changes in Vascular Adrenergic Signaling: Clinical and Mechanistic Implications. Ageing Research Reviews, 2, 169-190. http://dx.doi.org/10.1016/S1568-1637(02)00063-6

[25] Petrofsky, J., Lee, S. and Cuneo, M. (2005) Effects of Aging and Type 2 Diabetes on Resting and Post Occlusive Hyperemia of the Forearm; the Impact of Rosiglitazone. BMC Endocrine Disorders, 5, 4. http://dx.doi.org/10.1186/1472-6823-5-4

[26] Forbes, G.B. and Reina, J.C. (1970) Adult Lean Body Mass Declines with Age: Some Longitudinal Observations. Metabolism-Clinical and Experimental, 19, 653-663. http://dx.doi.org/10.1016/0026-0495(70)90062-4

[27] Raza, M., Hameed, A. and Khan, M. (2011) Ultrasonographic Assessment of Renal Size and Its Correlation with Body Mass Index in Adults without Known Renal Disease. Journal of Ayub Medical College Abbottabad, 23, 64-68. 
[28] Odita, J.C. and Ugbodaga, Cl. (1982) Roentgenologic Estimation of Kidney Size in Adult Nigerians. Tropical and Geographical Medicine, 34, 177-179.

[29] Fernandes, M.M., Lemos, C.C., Lopes, G.S., Madeira, E.P., Santos, O.R., Dorigo, D. and Bregman, R. (2002) Normal Renal Dimensions in a Specific Population. International Brazilian Journal of Urology, 28, 510-515.

[30] Inomata, S. (1993) Renal Hypertrophy as a Prognostic Index for the Progression of Diabetic Renal Disease in NonInsulin-Dependent Diabetes Mellitus. Journal of Diabetes and Its Complications, 7, 28-33. http://dx.doi.org/10.1016/1056-8727(93)90020-Y

[31] Zerbini, G., Bonfanti, R.N., Meschi, F., Bognetti, E., Paesano, P.L., Gianolli, L., Querques, M., Maestroni, A., Calori, G., Del Maschio, A., Fazio, F., Luzi, L. and Chiumello, G. (2006) Persistent Renal Hypertrophy and Faster Decline of Glomerular Filtration Rate Precede the Development of Microalbuminuria in Type 1 Diabetes. Diabetes, 55, 26202625. http://dx.doi.org/10.2337/db06-0592

[32] Adibi, A., EmamiNaini, A., Salehi, H. and Matinpour, M. (2008) Renal Cortical Thickness in Adults with Normal Renal Function Measured by Ultrasonography. Iranian Journal of Radiology, 5, 163-166.

[33] Beland, M.D., Walle, N.L., Machan, J.T. and Cronan, J.J. (2010) Renal Cortical Thickness Measured at Ultrasound: Is It Better than Renal Length as an Indicator of Renal Function in Chronic Kidney Disease? American Journal of Roentgenology, 195, 146-149. http://dx.doi.org/10.2214/AJR.09.4104

[34] ANAES (2003) Diagnostic de l'insuffisance rénale chronique chez l'adulte: Texte des recommandations Septembre 2002. Diabetes \& Metabolism, 29, 315-324.

[35] Muthusami, P., Ananthakrishnan, R. and Santosh, P. (2014) Need for a Nomogram of Renal Sizes in the Indian Population-Findings from a Single Centre Sonographic Study. Indian Journal of Medical Research, 139, 686-693.

[36] Bakker, J., Olree, M., Kaatee, R., de Lange, E.E., Moons, K.G., Beutler, J.J. and Beek, F.J. (1999) Renal Volume Measurement: Accuracy and Repeatability of US Compared with That of MR Imaging. Radiology, 211, 623-628. http://dx.doi.org/10.1148/radiology.211.3.r99jn19623

[37] Rigalleau, V., Garcia, M., Lasseur, C., Laurent, F., Montaudon, M., Raffaitin, C., Barthe, N., Beauvieux, M.C., Vendrely, B., Chauveau, P., Combe, C. and Gin, H. (2010) Large Kidneys Predict Poor Renal Outcome in Subjects with Diabetes and Chronic Kidney Disease. BMC Nephrology, 11, 1471-2369. 
Scientific Research Publishing (SCIRP) is one of the largest Open Access journal publishers. It is currently publishing more than 200 open access, online, peer-reviewed journals covering a wide range of academic disciplines. SCIRP serves the worldwide academic communities and contributes to the progress and application of science with its publication.

Other selected journals from SCIRP are listed as below. Submit your manuscript to us via either submit@scirp.org or Online Submission Portal.

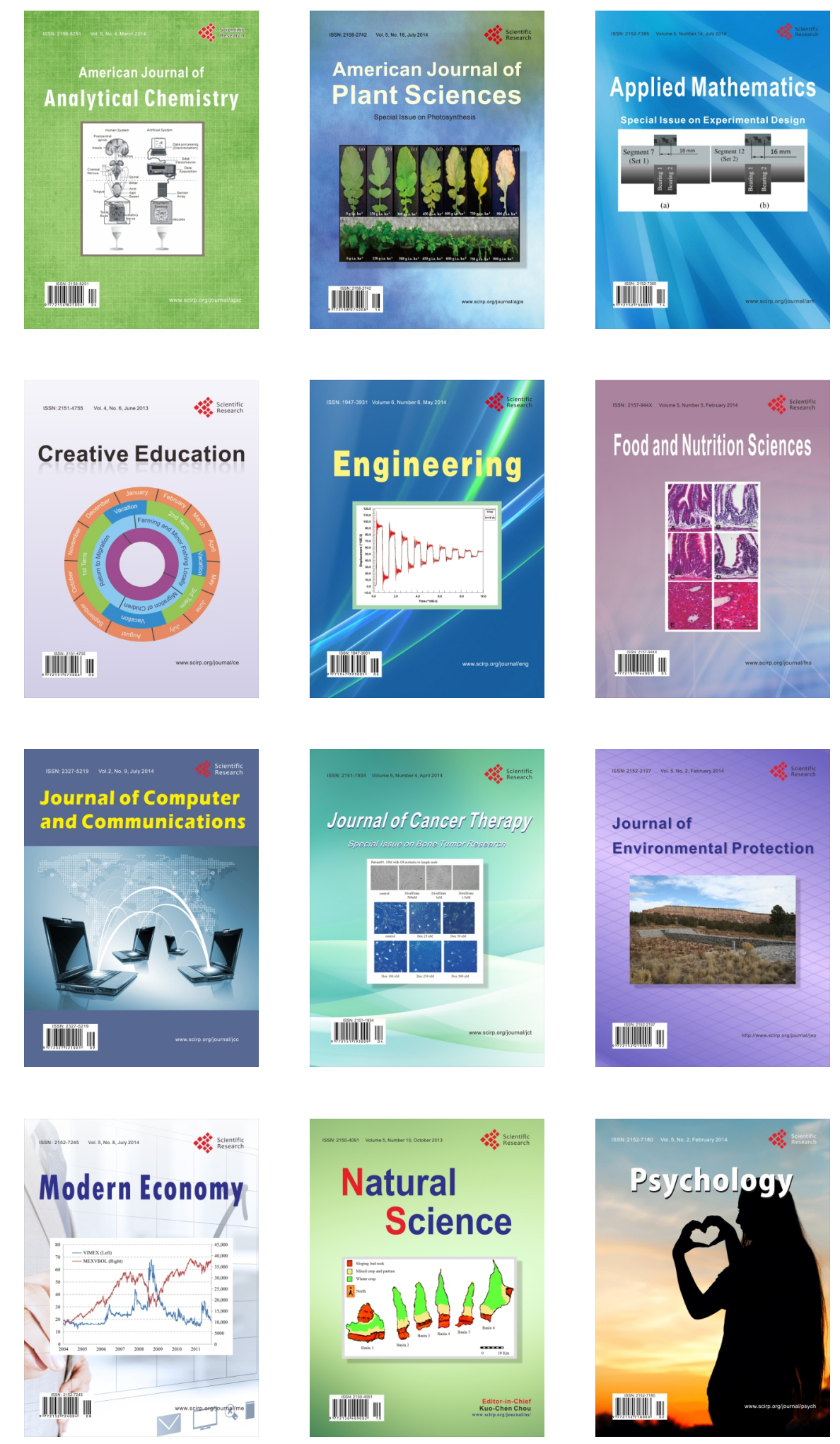